\title{
IMPLEMENTASI MODEL AGILE PADA MONITORING SUHU KOLAM IKAN DENGAN ALGORITMA FUZZY LOGIC BERBASIS INTERNET OF THING (IOT)
}

\author{
Jamal Maulana Hudin'1, Desi Susilawati ${ }^{2}$, Mohamad Alfi Faisal ${ }^{3}$ \\ 1STMIK Nusa Mandiri Jakarta \\ e-mail: jamal.jml@nusamandiri.ac.id \\ 2 AMIK BSI Sukabumi \\ e-mail: desi.dlu@bsi.ac.id \\ ${ }^{3}$ AMIK BSI Sukabumi \\ e-mail: mohamadalfi47@gmail.com
}

\begin{abstract}
Suhu adalah faktor penting yang dapat mempengaruhi produksi dan metabolism ikan. Suhu air memiliki pengaruh yang dominan terhadap kelangsungan kehidupan ikan, Suhu air yang optimal untuk budidaya ikan adalah $25-30^{\circ} \mathrm{C}$. Menjaga suhu air kolam agar selalu dalam kondisi optimal memerlukan pemantauan dan pengontrolan secara terusmenerus, karena suhu dapat berubah akibat pengaruh cuaca dan lingkungan. Penjadwalan alat akan aktif atau tidak yaitu menggunakan metode fuzzy logic yang akan mengontrol secara real time pada kolam ikan. Pada penelitian ini dirancang sebuah sistem yang bisa memantau dan mengontrol secara otomatis suhu air pada kolam ikan melalui jaringan internet. dalam pengujian sensor suhu yang digunakan, hasil pembacaannya dibandingkan dengan thermometer. Sistem ini menggunakan NodeMcu, sensor suhu DS18B20, serta aplikasi Cayenne sebagai platform lot. Sistem monitoring yang dirancang dapat memberikan informasi kondisi suhu air secara realtime. Sistem kontrol akan menyala secara otomatis ketika suhu berada diluar rentang normal. Pada penerapan sistem jika suhu kolam di bawah $25^{\circ} \mathrm{C}$ akan memunculkan notifikasi "Bahaya DINGIN" dan jika suhu kolam di atas $30^{\circ} \mathrm{C}$ makan akan memunculkan notifikasi "Bahaya PANAS".
\end{abstract}

Kata Kunci: fuzzy logic, Suhu, Kolam ikan, Cayenne, NodeMcu, DS18B20

\section{Pendahuluan}

Suhu pada kolam ikan merupakan salah satu faktor penting yang dapat mempengaruhi produksi dan metabolisme ikan, perubahan suhu di kolam ikan dipengaruhi oleh beberapa faktor yaitu radiasi matahari, suhu udara, cuaca, dan iklim (Wahyuni, 2018)Suhu air yang baik adalah antara $25^{\circ} \mathrm{C}-30^{\circ} \mathrm{C}$, pada derah yang suhu air nya relatif rendah atau pun tinggi perlu pemanas atau pendingin untuk mencapai suhu yang relatif stabil (Adi Aldaka, Ranu dan Julius, M, 2013:1).

Metode fuzzy logic merupakan salah satu komponen pembentuk soft computing. Logika fuzzy pertama kali di perkenalkan oleh Prof. Lotfi A. Zadeh pada tahun 1965. Contoh penggunaan fuzzy logic dalam bidang kontrol seperti yang telah dikembangkan oleh para peneliti sebelum nya (IImiah \& Tarigan, 2013:1). Keuntungan menggunakan sistem fuzzy salah satu nya yaitu pengontrolan suhu secara otomatis pada kolam ikan sesuai dan sebagai patokan untuk mengaktifkan notifikasi (Bahtiar, 2015:1).

Menurut (Junaidi, 2016), (internet of thing (IOT) adalah struktur di mana objek disediakan dengan identitas eksklusif dan kemampuan untuk pindah data melalui jaringan internet tanpa memerlukan dua arah anatara manusia ke manusia tanpa harus mendatangi objek yang akan kita kontrol. Oleh sebab itu dengan intenet of thing pengontrolan suhu pada kolam ikan akan sangat mudah tanpa harus kita mendatangi kolam ikan yang akan kita kontrol cukup dengan melihat mobile.

Model pengembangan perangkat lunak yang digunakan yaitu Model Agile dimana pengembangan perangkat lunak berdasar pada prinsip-prinsip yang sama atau pengembangan sistem jangka pendek yang memerlukan adaptasi cepat dari pengembangan terhadap perubahan dalam bentuk apapun(Muslim \& Retno, 2014), 
Perubahan Suhu mempengaruhi karakteristik pola perubahan suhu kolam ikan, serta akan berdampak langsung atau tidak langsung terhadap proses fisiologi pertumbuhan dan kelangsungan hidup biota air khusus nya ikan yang di budidayakan (Wahyuni, 2018). Dengan pemanfaatan teknologi dalam memonitoring suhu kolam ikan yang menggunakan internet sebagai media pengirim data dari Board mikrokontroler NodeMcu dengan sensor DS18b20 akan mengirim data ke perangat mobile dengan cyenne sebagai platform, dengan demikian, proses kontrol suhu kolam ikan dapat dilakukan dengan mudah dan cepat, walaupun user tidak berada langsung di tempat.

\section{Metode Penelitian}

\subsection{Teknik Pengumpulan Data}

Menurut (Yamin, 2016) Metode

pengumpulan data adalah teknik atau cara

yang dilakukan oleh peneliti untuk

mengumpulkan data. Pengumpulan data

dilakukan untuk memperoleh informasi

yang dibutuhkan dalam rangka mencapai

tujuan penelitian, tahapan dalam

pengumpulan data yaitu:

\section{a. Observasi}

Pada penelitian ini dilakukan pengamatan langsung ke lokasi penelitian yaitu SMKN 1 Cibadak,

b. Wawancara

Pengumpulan data dilakukan melalui wawancara/secara lisan dan tertulis terhadap pakar tentang suhu pada kolam ikan.

\section{c. Studi Pustaka}

Perpustakaan, web, dan jurnal-jurnal.

\subsection{Model Pengembangan Sistem \\ a. Sistem Pakar}

Sistem pakar adalah aplikasi berbasis komputer yang digunakan untuk menyelesaikan masalah sebagaimana yang dipikirkan oleh pakar. Pakar yang dimaksud di sini adalah orang yang memiliki keahlian khusus yang dapat menyelesaikan masalah yang tidak dapat diselesaikan oleh orang awam (Hidayat \& Gumilang, 2017)

\section{b. Artifical Intelligence}

Kecerdasan Buatan atau Artificial Intelligence adalah teknik yang digunakan untuk meniru kecerdasan yang dimiliki oleh makhluk hidup manapun benda mati untuk menyelesaikan sebuah persoalan (Ahmad, 2017).

\subsubsection{Pengembangan Pakar}

Metode yang digunakan adalah penerapan algoritma fuzzy logic. Logika fuzyy adalah suatu cara tepat untuk memetakan suatu ruang input ke dalam suatu ruangan output. Teknik ini menggunakan teori matematis himpunan fuzzy, logika fuzzy berhubungan dengan ketidakpastian yang telah menjadi sifat alamiah manusia. Ide dasar dari logika fuzzy muncul dari perinsip ketidakjelasan, pertama kali dibangun dengan menganut prinsip teori himpunan (Syaeful Anas Aklani, 2014)

\subsubsection{Pengembangan Software}

A. Analisa Kebutuhan Sistem

Proses perancangan sistem perangkat keras maupun perangkat lunak serta implementasinya, secara garis beras, seluruh sistem dibangun di atas sebuah modul NodeMcu sebagai microkontroler nya. DS18b20 sebagai sensor pengontrolan suhu air dalam kolam ikan, cayenne sebagai platform internet sekaligus sebagai server yang mampu menyimpan project yang sedang di buat. Agile sebagai modul pengembangan aplikasinya, dan kendali fuzzy logic-nya berupa implementasi secara perangkat lunak.

\section{B. Desain}

Dikarenakan program ini akan diterapkan dalam sistem operasi Android dan Komputer, maka proses desain interface dari program sistem pakar ini menggunakan Cayenne sebagai platform IOT pengembang dengan sistem draganddrop milik myDevices, Cayenne menyediakan akses untuk fitur-fitur Arduino saat akan digunakan menjadi board Internet of Things alternatif. Pengguna dapat memanfaatkan berbagai macam shield untuk digunakan sebagai platform IoT dengan pengaturan cukup mudah, termasuk di dalamnya Wifi, BLE, IR, NFC, dan lain sebagainya. Platform yang dibangun dengan tujuan mempermudah pembangunan ekosistem loT (Artono \& Susanto, 2017). 


\section{Testing}

Teknik pengujian yang paling sesuai untuk menguji sistem pakar yakni dengan menggunakan teknik Black box testing. Karena spesifikasi fungsional dari perangat lunak Tester dapat mendefinisikan kumpulan kondisi input dan melakukan pengetesan pada spesifikasi fungsional program.

\section{Implementasi}

Untuk melakukan kegiatan spesifikasi rancangan logika dan alat ke dalam kegiatan yang sebenarnya dari sistem pakar yang akan dibangun atau dikembangkan, lalu mengimplementasikan sistem yang baru tersebut kedalam salah satu bahasa pemograman yang berbasis mobile computing.

\section{Hasil dan Pembahasan}

3.1 Algoritma Sistem Pakar

a. Himpunan Fuzzy dan Fungsi Keanggotaannya

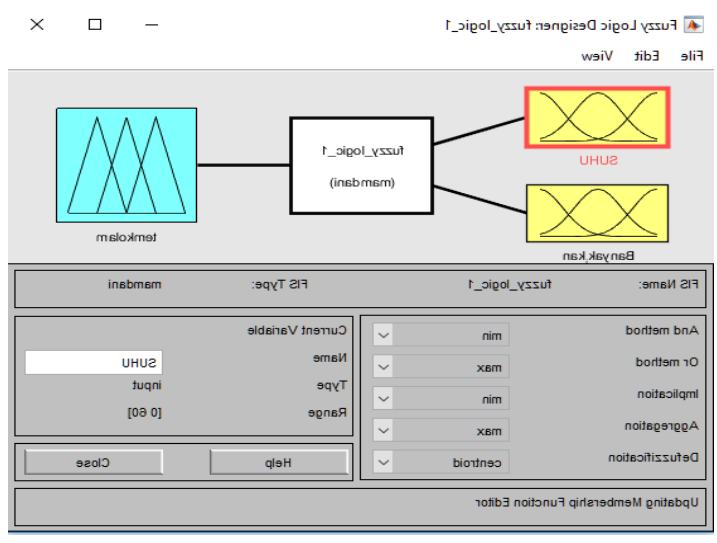

Gambar 1. Himpunan fuzzy

Berdasarkan data spesifikasi dari pakar, suhu terkecil $10 \mathrm{C}^{0}$ dan terbesar $30 \mathrm{C}^{0}$ dengan ini bisa dibuat range suhu berada diantara $0 \mathrm{~s} / \mathrm{d} 60 \mathrm{C}^{0}$.

Range $=\left[\begin{array}{ll}0 & 60\end{array}\right]$

Dalam hal ini variable suhu dibagi menjadi dua himpunan fuzzy yaitu, RENDAH dan TINGGI.

DINGIN Type $=$ trampf $\quad$ parameter $=$ [0 $\left.\begin{array}{llllll}0 & 0 & 10 & 30\end{array}\right]$

NORMAL Type $=$ trimf $\quad$ parameter $=$ [10 3050 ]

PANAS Type $=$ trampf $\quad$ parameter $=$ [30 506060 60]

\section{b. Rules Fuzzy}

1.IF SUHU = DINGIN and Banyak ikan SEDIKIT THEN Temkolam = DINGIN

2.IF SUHU = NORMAL and Banyak ikan SEDIKIT THEN Temkolam $=$ NORMAL

3.IF SUHU = PANAS and Banyak ikan SEDIKIT THEN Temkolam = PANAS

4.IF SUHU = DINGIN and Banyak ikan BANYAK THEN Temkolam $=$ NORMAL

5.IF SUHU $=$ NORMAL and Banyak ikan BANYAK THEN Temkolam $=$ NORMAL

6.IF SUHU = PANAS and Banyak ikan BANYAK THEN Temkolam = PANAS

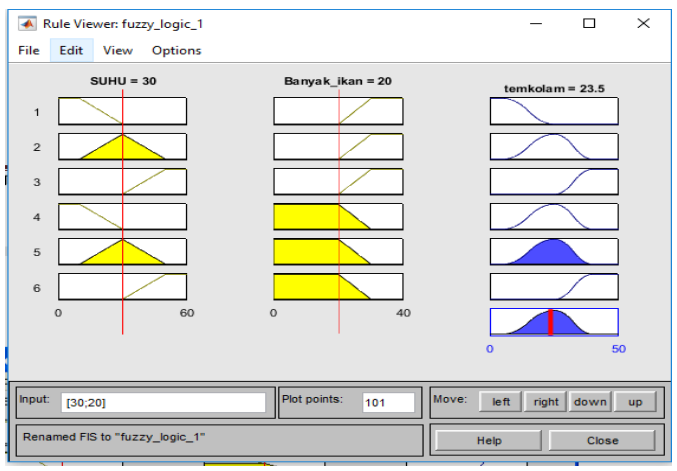

Gambar 2. Rule Fuzzy

Untuk menjawab pertanyaan berikut :

Berapa suhu temperature kolam dihasilkan sistem kontrol tersebut bila pada saat itu suhu menunjukkan angka 30 Celcius sedangkan banyak ikan 20 ekor?

Ini berarti variabel input :

SUHU $=30$ Banyak ikan $=20$

Untuk melihat berapa besar variabel output yang dihasilkan, maka lihat lah gambar di atas.

\section{c. Cara kerja sistem}

Sensor suhu melakukan pendektesian kondisi air kolam, hasil pendeteksi lalu di kirim ke NodMcu untuk kemudian diolah. dan dikirim menuju aplikasi cayenne sehingga $\mathrm{k}$ ondisi suhu air kolam dapat dimonitoring lewat aplikasi tersebut. 


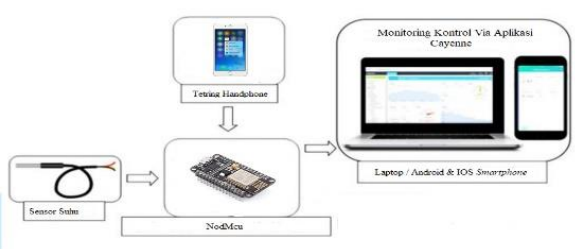

Gambar 3. Rancangan Perangkat

d.

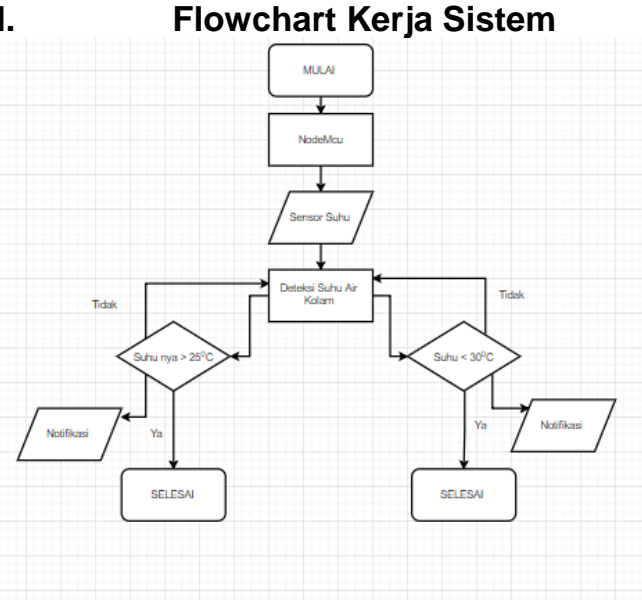

Gambar 4. Flowchart

\section{e. Perancangan Sensor Suhu}

Sensor yang digunakan untuk mendeteksi nilai suhu air kolam adalah dengan DS18b20 rangkaian sensor harus ditambahkan resistor pull-up sebesar 4.7 $\mathrm{K} \Omega$.

Kabel warna kuning menghubungkan pin $\mathrm{DQ}$ sensor dengan resistor dan pin 1 NodeMcu, kabel merah menghubungkan pin VDD sensor ke resistor lalu menuju pin 3V NodeMcu, kemudian kabel hitam menunjukan hubungan antara pin GND sensor dengan Nodemcu.

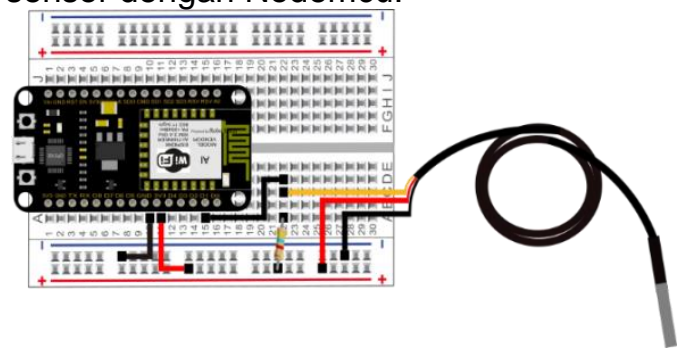

Gambar 5. Wiring Sensor Suhu

\subsection{Percancangan Objek}

\subsubsection{Pengumpulan Data Pakar}

Pada saat proses pengumpulan data pakar, penulis melakukan wawancara kepada pihak sekolah yang sesuai pakarnya.

\subsubsection{Objek Pakar}

Salah satu objek pakar yang menjadi narasumber dalam pengumpulan data pakar adalah Ilham Ahmadian yang memegang jabatan sebagai guru di SMKN 1 Cibadak.

\subsection{Implementasi Program}

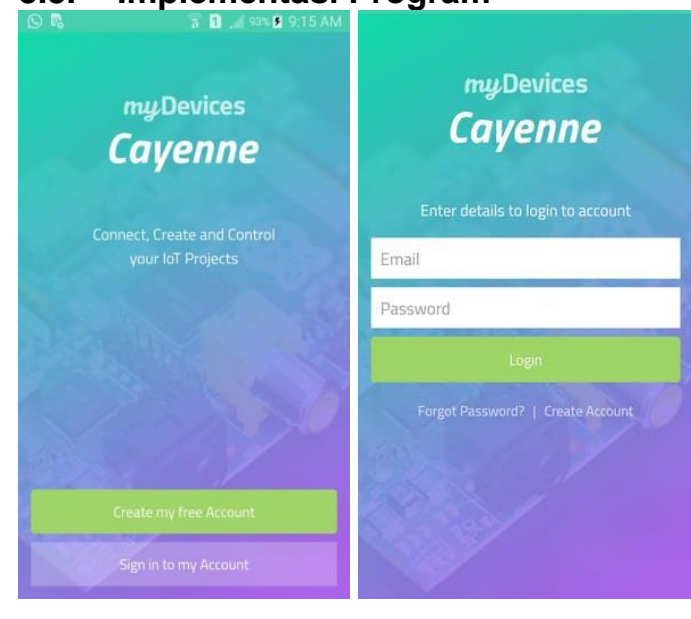

\section{Gambar 6. Menu Gambar 7. Login}

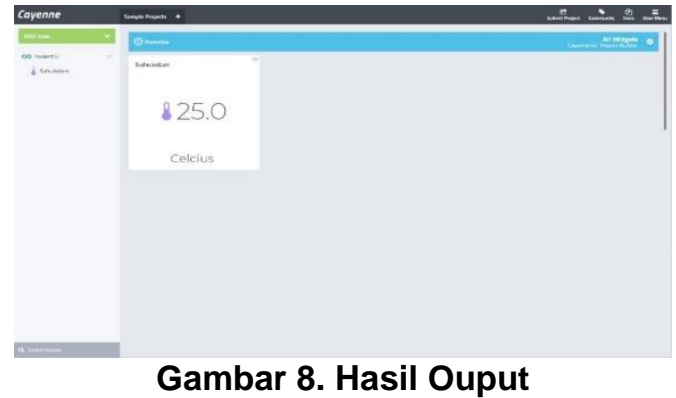

\subsection{Hasil Pengujian}

Pengujian software dalam penelitian ini dilaksanakan oleh pihak pembuat, sedangkan untuk metode pengujian yang digunakan adalah pengujian black box.

\subsubsection{Black Box Testing}

Metode ini digunakan untuk mengetahui apakah perangkat lunak berfungsi dengan benar. Adapun hal-hal yang akan diujikan menggunakan metode black box ini adalah sebagai berikut : 


\begin{tabular}{ccc}
\hline \multirow{2}{*}{ Menit } & \multicolumn{2}{c}{ Hasil Pengujian Suhu $\left({ }^{\circ} \mathrm{C}\right)$} \\
& Sensor & Thermometer \\
\hline 1 & 25,31 & 25,5 \\
2 & 25,25 & 25,4 \\
3 & 25,19 & 25,3 \\
4 & 25,12 & 25,3 \\
5 & 25,19 & 25,4 \\
\hline Rata- & 25,21 & 25,36 \\
rata & & \\
\hline
\end{tabular}

Tabel 1. Pengujian Sensor Suhu

Table 1 adalah pengguna sensor suhu DS18B20 dalam 5 menit dengan pengamambilan data tiap menit.

\section{b. pengujian Monitoring dari cayenne}

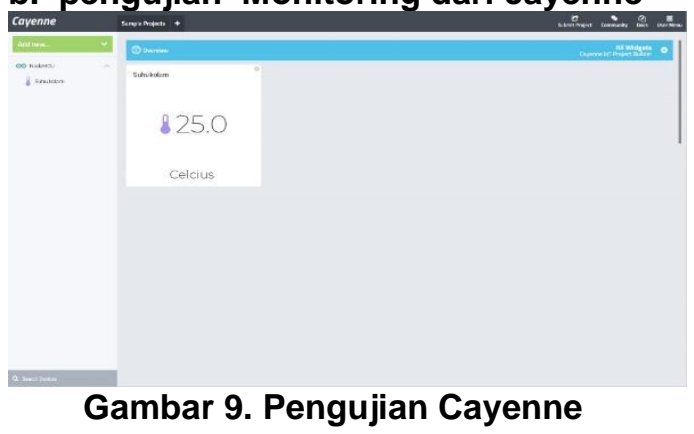

Pengujian monitoring pada aplikasi Cayenne dilakukan untuk mengetahui bahwa hasil pembacaan sensor suhu dapat di lihat pada aplikasi secara realtime

\subsubsection{Support}

Spesifikasi hardware dan software yang mendukung untuk menjalankan aplikasi sistem pakar alat prototype yang dibuat.

\subsubsection{Spesifikasi Hardware dan Software}

\begin{tabular}{|c|c|}
\hline Kebutuhan & Keterangan \\
\hline Sistem Operasi & $\begin{array}{c}\text { Android 2.2 Froyo } \\
\text { sampai Android 8.1.0 } \\
\text { Oreo }\end{array}$ \\
\hline Processor & $1,0 \mathrm{GHz}$ atau selebihnya \\
\hline Memory & $512 \mathrm{MB}$ atau selebihnya \\
\hline Layar & $\begin{array}{c}\text { Touch Screen 3,7 Inch } \\
\text { WVGA (480x800: hdpi) }\end{array}$ \\
\hline & Tabel 2. Tabel Spesifikasi Hardware dan \\
& Software
\end{tabular}

\section{Kesimpulan}

Berdasarkan pembahasan pada babbab sebelumnya, dapat diambil kesimpulan dari pembuatan sistem pakar alat prototype menggunakan Fuzzy logic Mamdani diantaranya:

a. Sistem pakar dibuat agar membantu para peternak ikan khususnya yang kerja dilapangan agar dengan mudah mendapatkan informasi dan memonitoring mengenai perubahan suhu kolam ikan.

b. Dengan sensor DS18B20 dan konsep internet of things dengan aplikasi cayenne dapat mempermudah pengontrolan./ monitoring suhu pada kolam ikan.

c. Keputusan dengan menggunakan metode Algoritma fuzzy logic sangat cocok untuk penyelesaian suatu masalah khusus nya pada perubahan suhu dan parameter kolam ikan.

d. Sistem pakar ini memberikan informasi kepada pekerja lapangan dikolam ikana agar dengan mudah menentukan suhu dan banyaknya ikan dalam temperature kolam.

\section{Referensi}

Bahtiar, A. (2015). Rancang Bangun Pengontrol Suhu dan Kekeruhan Air Kolam Ikan Patin Berbasis Fuzzy Logic, 7-12.

Hidayat, H. A., \& Gumilang, G. (2017). Sistem Pakar Diagnosis Penyakit Yang Disebabkan Oleh Rokok Dengan Metode Forward Chaining. Jutekin, 3(1), 27-36. Retrieved from http://jurnal.stmik-

dci.ac.id/index.php/jutekin/article/down load/179/140

Ilmiah, T., \& Tarigan, P. (2013). SISTEM PENGENDALI PENDINGIN RUANGAN MENGGUNAKAN FUZZY LOGIC BERBASIS MIKROKONTROLER ATMEGA 8535, 86-92.

Junaidi, A. (2016). Internet of Things , Sejarah , Teknologi Dan Penerapannya: Review Internet of Things, Sejarah, Teknologi Dan Penerapannya: Review. Jurnal IImiah Teknologi Infromasi Terapan, I(AUGUST 2015), 62-66. 
Muarif, M. (2016). 1913-3520-1-Sm, 1(2), $1-9$.

Muslim, M. A., \& Retno, N. A. (2014). Implementasi Cloud Computing Menggunakan Metode Pengembangan Sistem Agile, 1(1), 29-38.

Ranu Adi Aldaka, Ir. M. Julius ST, M. (2013). Sistem Otomatisasi Pengkondisian Suhu, pH, dan Kejernihan Air Kolam Pada Pembudidayaan, 1-7.

Syaeful Anas Aklani. (2014). Metode Fuzzy Logic Untuk Evaluasi Kinerja Pelayanan Perawat ( Studi Kasus: RSIA Siti Hawa Padang ). eDikInformatika, 1(1), 30.

Wahyuni, T. 2018. (n.d.). wawancara 2 BBAT Sukabumi Tentang perubahan suhu pada kolam ikan.

Yamin, M. (2016). BAHASA INDONESIA TEKNIK PENGUMPULAN DATA DALAM PENELITIAN Kelompok $X$ : Nindi Sri Kurnia Nurmaliza Novi Dera Wati Miko Hendra Eko Setiyono Moderator : Wikendari Puri, 1-14. 